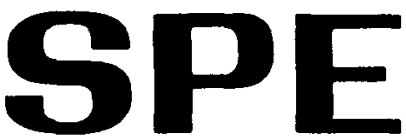
(

IADC/SPE 23935

\title{
An Evaluation of Flowmeters for the Detection of Kicks and Lost Circulation During Drilling
}

Society of Petroleum Engineers

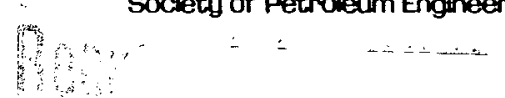

SAND- $-91-1848 \mathrm{C}$

DE92 004209

by D. M. Schafer*, G. E. Loeppke, D. A. Glowka*, and D. D. Scott, Sandia National Laboratories, and E. K. Wright, Ktech Corp.

* SPE Member

This paper was prepared for presentation at IADC/SPE 1992 Drilling Conference held in New Orleans, Louisianna, February 18-21, 1992. The material is subject to correction by the author. Permission to copy is restricted to an abstract of not more than 300 words. Write SPE, P.O. BOx 833836. Richardson, Texas 75083-3836.

\section{ABSTRACT}

An independent evaluation of current industry standard and state-of-the-art drilling fluid inflow and outflow meters was conducted during the drilling of a geothermal exploratory well. Four different types of fluid inflow meters and three different types of fluid outflow meters were tested and evaluated during actual drilling operations. The tested dirilling fluid inflow meters included conventional pump stroke counters, rotary pump speed counters, magnetic flow meters, and a Doppler ultrasonic flow meter. On the return flow line, a standard paddle meter, an acoustic level meter, and a prototype rolling float meter were evaluated to measure drilling fluid outflow rates. The prototype outflow meter utilizes a rolling float which rides on the surface of the flow thereby measuring the fluid height in the pipe. Both the prototype meter and the conventional paddle meter were also extensively tested under a variety of drilling conditions in a fullscale laboratory test facility. The meters were evaluated and compared on the basis of reliability and accuracy, and the results are presented in the paper.

\section{INTRODUCTION}

The economic and environmental climates in the drilling industry dictate that drilling be conducted with increasing efficiency and safety. Controlling well kicks and stopping or preventing lost circulation are high on the list of things that can be done to accomplish these goals. Studies have shown that measurement of delta flow (outflow minus inflow) is the best method for timely diagnosis of kicks and lost circulation while drilling. A key element for successful detection of these events is adequate rig instrumentation.

Finding instrumentation that can provide the necessary accuracy and response time is a challenge. Studies by Orban et al. [1] concluded that a delta flow accuracy of 25 to $50 \mathrm{gpm}$ is required to successfully detect influx or loss during the drilling process. Assuming a pumping rate of $1000 \mathrm{gpm}$, the combined accuracy of the inflow and outflow measurements should then be $2.5 \%$ (or $+/-1.25 \%$ ). This is much better accuracy than that of present field equipment and approaches that of many laboratory instruments. Flow meters with the desired accuracy exist, but the problem becomes practical application and acceptance by the industry.

The challenge then is to provide a useful system for measuring delta flow that will be widely accepted and eventually found on every drilling rig where kicks and loss circulation must be controlled. Experience shows that this will require a system with the following characteristics: low impact on the drill rig hardware and instrumentation, low cost, easy installation and maintenance by personnel that are normally present at the drill site, and minimum interference with the return flow.

Inflow measurements are almost always made on drill rigs by counting the mud pump strokes over a period of time and calculating a flow rate using volume per stroke and an assumed pump efficiency. This method is acceptable for setting the mud pump rate, but does not have the accuracy nor response time desired for delta flow measurement.

Due to the difficulty of measuring the outflow rate in the return line, outflow measurements are not always made. The most common means of measuring outflow is the paddlemeter. It is the instrument of choice not because of its ability to measure flow rate, but because it meets the requirements for practical application listed above. In fact, it is often calibrated in percent of full scale deflection and is used more as an indicator than as a measurement of flow. One logging company has measured delta flow for the purpose of detecting and controlling kicks. The company uses an ultrasonic meter for outflow measurement, coupling it to inflow measurements with extensive software for determining actual delta flow $[1,2]$. Others have measured delta flow using magnetic flowmeters in both the inflow and outflow lines [3-5].

The most common method of detecting delta flow is by monitoring changes in mud tank volume as measured by pit level meters. While this system provides a measure of the total pit volume gained or lost over a period of time, it does not permit rapid detection or accurate quantification of wellbore production or loss rates which are essential data for rapid response to gas kicks or lost circulation [5].

The purpose of this paper is to present an analysis of laboratory and field test results of various inflow and outflow metering techniques to determine their suitability for delta flow measurement by comparing their accuracy and reliability. The performance of a developmental rolling float meter designed to accurately measure the outflow in the flow line is also presented. 


\section{DISCLAIMER}

This report was prepared as an account of work sponsored by an agency of the United States Government. Neither the United States Government nor any agency Thereof, nor any of their employees, makes any warranty, express or implied, or assumes any legal liability or responsibility for the accuracy, completeness, or usefulness of any information, apparatus, product, or process disclosed, or represents that its use would not infringe privately owned rights. Reference herein to any specific commercial product, process, or service by trade name, trademark, manufacturer, or otherwise does not necessarily constitute or imply its endorsement, recommendation, or favoring by the United States Government or any agency thereof. The views and opinions of authors expressed herein do not necessarily state or reflect those of the United States Government or any agency thereof. 


\section{DISCLAIMER}

Portions of this document may be illegible in electronic image products. Images are produced from the best available original document. 
Laboratory test results of this prototype meter are compared with those obtained with the paddlemeter. The performance and reliability of these and other transducers during field operation in August and September, 1991, at the Long Valley Exploratory well near Mammoth Lakes, $\mathrm{Ca}$. are then evaluated.

\section{EFFECTS OF FLOW FIELD CHARACTERISTICS}

The drilling fluid flows from the mud pump to the entrance of the wellbore through pipe that is completely full of fluid. Turbulence criteria for non-newtonian flow in such geometries indicates turbulent pipe flow under most conditions of practical interest in drilling [6]. This means the flow has a relatively flat velocity profile across most of the pipe cross-section, with steep velocity gradients near the pipe wall. Flow measurement techniques for such flows include intrusive and non-intrusive methods for quantifying the mean fluid velocity and multiplying it by the cross-sectional area to determine the total flow rate.

Drilling fluid returning to the mud pit from a wellbore undergoes gravity-fed flow down an inclined pipe, the return flow line, that has a cross-section only partially filled with fluid. Consequently, the fluid undergoes acceleration after it enters the pipe, increasing in average velocity and decreasing in height. The height of the fluid continues to decrease until the force due to gravity is directly balanced by the force due to friction at the pipe walls; at this point uniform flow conditions exist and both the height and average velocity of the fluid remain steady. Both experimental and theoretical results indicate that at a given location, an increase in flow rate results in a corresponding increase in fluid height; this is illustrated in Figure 1.

At a given location along the return flow line, the velocity of the fluid increases from zero at the pipe wall to a maximum near the top of the fluid cross-section. Laboratory pitot-tube measurements [7] indicate that under most flow rates of interest, the flow is highly turbulent, with significant time-dependent variations in local velocities, surface waves that travel down the flow line, a flat velocity profile in the center of the fluid crosssection, and steep velocity profiles near the pipe wall. Theoretical results discussed in Ref. 7 also indicate that the mean fluid velocity at a given flow cross-section approaches an asymptote as flow rate increases; the same behavior of the maximum fluid centerline velocity has been confirmed experimentally. The consequence is that the fluid height in an inclined, partially-filled pipe is a more sensitive measure of the total flow rate than are the mean or maximum fluid velocities. Flow measurement techniques for such flows include intrusive and non-intrusive methods for quantifying the fluid level, which is then correlated with the total flow rate.

\section{DESCRIPTION OF TESTED FLOWMETERS}

Several types of flowmeters were tested in the laboratory and field. The inflow meters tested included a conventional mud pump stroke counter, a pump rotary speed transducer, a magnetic flowmeter, and a Doppler ultrasonic flowmeter. The outflow meters tested included a conventional paddlemeter, a commercial acoustic level meter, and a rolling float meter.

The mud pump stroke counter employs a limit switch that opens and closes with each stroke of the mud pump piston. The number of strokes detected in a given time period is then multiplied by the volume of fluid pumped during each stroke and the pump efficiency to determine the total output rate of the pump. Shortcomings of this type of flowmeter include: slow response due to the relatively long time period (typically 1-2 seconds) between strokes; and inaccuracies due to uncertainties in pump efficiency, which changes with pump pressure and piston seal wear.

The pump rotary speed transducer uses an optical encoder that provides pulses at a rate proportional to the rotary speed of the mud pump drive shaft. By multiplying this rotary speed by the pump efficiency and the volume of fluid pumped during each rotation of the drive shaft, the total output rate of the pump is determined. The encoder produces sixty pulses per revolution of the shaft and there are 4.79 revolutions per pump stroke; therefore, the encoder output frequency is 287 times the stroke frequency. This method does not suffer from the slow response of the pump stroke counter because the optical pickup senses partial rotations; however, it does share the same uncertainty as the strake counter with respect to pump efficiency.

The magnetic flowmeter establishes a magnetic field in the fluid flowing through it. Perturbations in the magnetic field are correlated with fluid velocity and multiplied by the flow area to determine the flow rate through the meter. This type of flowmeter provides exceptional accuracy, and the output signal is not affected significantly by changes in fluid properties as long as the fluid is electrically conductive. Disadvantages include high cost and pressure limitations, which generally require the magnetic flowmeter to be installed on the pump inlet. Its use is limited to water-based drilling mud.

The Doppler ultrasonic flowmeter employs a non-intrusive transducer that clamps to the outside surface of the pipe. The transducer emits ultrasonic pulses and detects the Doppler shift of the returning pulses as they are reflected off particles in the fluid. The Doppler shift is a quantified function of the mean fluid velocity, which is multiplied by the flow area to determine the total flow rate through the pipe. Shortcomings include inaccuracies caused by mechanical and electrical noise in the drilling environment and the requirement that solid or gaseous particles be present in the flow.

The paddlemeter commonly used in drilling operations employs a single, spring-mounted plate or paddle that extends down into the flow and is deflected upward by fluid impinging on it. The amount of deflection is a function of the impact force of the fluid on the paddle, which in turn is a function of the fluid height and velocity and, thus, the flow rate. The paddle deflection is calibrated to provide a measure of the flow rate. Limitations experienced with this meter are poor accuracy and repeatability. Consequently, this meter is often used in the field in a qualitative manner, with the output presented in terms of a fraction of full paddle deflection rather than absolute flow rate.

The acoustic level meter uses a transducer mounted above the fluid surface that emits acoustic pulses and detects the return pulses echoed off the fluid surface. The echo time is proportional to the distance between the transducer and the fluid surface, which in turn is a function of the flow rate through the pipe. The primary disadvantage of this type of meter is that the temperature and composition of the air in the return flow line significantly affect the acoustic velocity and, therefore, the echo time. As a result, the data must be corrected to account for these effects.

The rolling float meter is a device developed at Sandia National Laboratories for the purpose of detecting and quantifying lost circulation encountered in drilling geothermal wells [7]. A schematic of the meter design is shown in Figure 2. It employs a rolling, counterbalanced float that rides the surface of the fluid in the return flow line. The vertical location or height of the float is closely related to fluid height and thus the flow rate. The float height is determined by measuring the angle of the pivot arm with a pendulum potentiometer. Prototype models of this transducer were also built with: a magnetic rotary sensor incorporated into the float in order to measure the spin rate of the float, which is a function of the fluid velocity in the flow line; and an adjustable dashpot to provide inertial damping of the pivot arm.

\section{LABORATORY TESTING}

Laboratory Flow Facility

The Wellbore Hydraulics Flow Facility represented in 
Figure 3 was constructed to provide full-scale simulation of fluid flow out of a wellbore during drilling. A $1000-\mathrm{gpm}(63-\mathrm{L} / \mathrm{s})$ slurry pump was used to pump drilling fluid from the mud tank, into a simulated wellbore, and down a 12-ft-long (3.7-m-long), inclined return flow line into the mud tank. The return flow line could be adjusted to any angle between 0 and 12.5 degrees with respect to horizontal. Both a 10 -inch $(25.4-\mathrm{cm})$, transparent plastic tube and a 12 -inch $(30.5-\mathrm{cm})$ steel pipe were used as the return line during different phases of the testing.

Outflow meters were evaluated against a 4-inch $(10.2-\mathrm{cm})$ magnetic flowmeter mounted in a section of full pipe between the pump and the simulated wellbore. The magnetic flowmeter was used as the standard measure of flow rate because of its excellent accuracy (within approximately $2 \%$ as measured in our facility and $\pm 0.5 \%$ as stated by the manufacturer) and its insensitivity to fluid properties. A throttle valve downstream of the pump was used to vary the flow rate over its full range of 0 $1000 \mathrm{gpm}(0-63 \mathrm{~L} / \mathrm{s})$.

\section{Laboratory Test Parameters}

A conventional paddlemeter and the rolling float meter were tested in the facility. Testing consisted of measuring the response of each flowmeter as the flow rate was increased from 0 to $1000 \mathrm{gpm}(63 \mathrm{~L} / \mathrm{s})$ in $50-\mathrm{gpm}(3.2-\mathrm{L} / \mathrm{s})$ increments. The flow rate was then decreased back to zero in $100-\mathrm{gpm}(6.3-\mathrm{L} / \mathrm{s})$ increments in order to test the repeatability of the flowmeter response. Approximately 30 seconds of data were recorded at each flow rate. These data were then averaged to determine the response of each flowmeter at each flow rate.

In addition to the flow rate, the test parameters included the circulating fluid type (water, water-based bentonite drilling mud, weighted drilling mud, and drilling mud with drill cuttings) and the return flow line slope (0-12.5 degrees). The design configuration of the rolling float meter was also varied to determine the optimal; wheel cross-section (4-inch oval, 3-inch oval, 2-inch "V", and 2-inch flat); wheel traction (tread, notread); wheel weight (counterbalance position); pivot arm length (7.7-9.5 inches); and inertial damping (dashpot setting).

\section{Laboratory Test Results}

The conventional paddlemeter was tested in the laboratory in both water and drilling mud. Lab testing showed significant hysteresis in the paddlemeter readings at low flow rates, in that the data obtained with increasing flow rate differed from the data obtained with decreasing flow rate. The overall response of the paddlemeter, however, did not exhibit the scatter and repeatability errors that are often experienced in the field. This may be due to the location of the meter in the return line, or the the difference in inflow pumps. It was determined, therefore, that field testing would be required for the evaluation of all outflow meters.

Float height measurements obtained with the rolling float meter in the laboratory demonstrated excellent repeatability with no hysteresis. In the transparent retum line, it was observed that the rolling float meter perturbs the flow to a much smaller degree than does the paddlemeter. Another finding during these tests was that dynamic pressures in the fluid tend to attract the rolling float to the surface of the fluid, causing the float to follow the fluid surface without bouncing free.

The rolling float meter was extensively evaluated during the course of laboratory testing. Measurements of the float's perimeter velocity showed that above $400 \mathrm{gpm}(25.2 \mathrm{~L} / \mathrm{s})$ rotation rate is independent of flow rate, which is consistent with the theoretical work discussed previously [7]. Therefore, it was determined that the float's rotary speed transducer is not a necessary feature of the meter. Also, an increase in net float weight (simulating the long-term accumulation of drilling mud on the float) had little effect on the performance of the rolling float meter [7].

The effects of fluid properties on the rolling float meter response are shown in Figure 4. These results were obtained by adding increased concentrations of barite to the bentonite mud. The results indicate that typical fluid viscosity and density changes have little effect on the float height measured with the rolling float meter. It was also found that the addition of typical concentrations of drill cuttings does not significantly affect the measured float height; thus, changes in rock penetration rates that cause changes in drill cutting concentrations should not affect performance of the meter.

Data obtained with different rolling float configurations were used to determine the optimal design. It was found that a 3-inch oval float cross-section provided the most repeatable results. It was discovered that traction caused by the presence of knobby treads on the float was necessary for the float to spin and give repeatable results. The length of the pivot arm proved to have little effect on the meter performance. Finally, it was concluded that the dashpot installed for inertial damping of the pivot arm was not necessary due to the manner in which the float is attracted to the surface of the fluid.

\section{FIELD TESTING}

The laboratory test results indicated that field testing of the rolling float meter was warranted. In addition, it was determined that simultaneous testing of various standard and non-standard inflow and outflow measurement techniques would permit a thorough evaluation of the relative accuracy and reliability of the various measurement techniques currently available to the industry. This field testing was conducted during phase-2 drilling of the Long Valley Exploratory Well, a joint U.S. Dept. of Energy/State of California exploratory well being drilled by Sandia National Laboratories in the Long Valley volcanic caldera near Mammoth Lakes, California, to investigate hydrothermal and advanced geothermal systems. Mud flow measurements were made and recorded every one to five minutes during most of the $1 \frac{1}{2}$-month drilling period for this phase of the well.

\section{Test Hardware Installation}

A conventional stroke counter was installed on each of the two mud pumps used at the rig. In addition, the drive shaft of each pump was fitted with an optical encoder to sense rotary speed. This was accomplished by simply securing the rotary shaft of each encoder to a tapered rubber stopper that was pressed into a threaded hole on the end of each drive shaft. The rubber stopper was then squeezed in the axial direction with the shaft-mounting hardware to radially expand the stopper and secure it within the hole.

A 10 -inch $(25.4-\mathrm{cm})$ magnetic flowmeter was installed on the inlet to each mud pump. The magnetic flowmeters were installed with approximately 8 feet $(2.4 \mathrm{~m})$ of straight pipe upstream of the meters. This was very close to the manufacturer's minimum recommended distance of ten pipe diameters for highly accurate readings. A Doppler ultrasonic flowmeter was attached externally to a vertical section of the standpipe at a location approximately ten feet above the mud pump level. An RTD temperature probe was externally attached to the standpipe and wrapped with fiberglass insulation. $A$ pressure transducer was also installed in the standpipe to read mud pump pressure.

The acoustic level meter, the prototype rolling float meter, and a conventional paddlemeter were mounted on the return flow line between the wellbore and the shale shakers. Because it does not perturb the flow, the acoustic level meter was mounted first in line, approximately 15 feet $(4.6 \mathrm{~m})$ from the wellbore. The paddlemeter, which disturbs the flow for several feet upstream and downstream of the paddle, was mounted 28 feet $(8.5 \mathrm{~m})$ from the wellbore. The rolling float meter was mounted 20 feet $(6.1 \mathrm{~m})$ from the wellbore, 5 feet $(1.5 \mathrm{~m})$ downstream of the acoustic level meter and 8 feet $(2.4 \mathrm{~m})$ upstream of the 
paddlemeter. An RTD temperature probe was also installed on the flow line, with the probe protruding directly into the mud flow. A catwalk was built parallel to the flow line to allow easy access to the various instruments.

\section{Elowmeter Calibration and Testing Procedures}

Since the three outflow meters did not directly measure fluid flow rate, a calibration was necessary. Meter calibrations were conducted at the beginning of phase- 2 drilling, when the pre-existing phase-1 hole was cased and no lost circulation or production was occurring. Calibrations were again conducted during the course of the field tests when meter settings or parameters were changed. These calibrations were conducted when pit level indicators measured no loss or gain of fluid.

Each of the flowmeters was calibrated against the magnetic flowmeter inflow measurements. Measurements were taken in increments of approximately 10 strokes $/ \mathrm{min}$, from no-flow conditions to the maximum output of the pumps (approximately $40-50$ strokes/min on each of two inlet pumps). When the desired flow rate was attained, meter outputs were read once per second for approximately 20-30 seconds, resulting in 20-30 data points at each of ten measured flow rates. The calibration data from each meter were fit with a third-order polynomial using a least-squares curve fit. The resulting equations were then used to convert raw signals to flow rates during drilling.

The calibration procedure described above required less than 15 minutes and resulted in ten measured flow rates. However, subsequent data analysis has shown that as few as four measured flow rates can result in an accurate calibration curve, with two points at low flow rates (e.g., at $0 \mathrm{gpm}$ and 100 gpm) and two points at high flow rates (e.g., $800 \mathrm{gpm}$ and 900 $\mathrm{gpm})$. In addition, five or more equally-spaced measured flow rates which include both zero flow and high flow rates will result in an accurate calibration. Thus, the time necessary for outflow meter calibration could feasibly be reduced from 15 minutes to 5-10 minutes.

The outflow meter calibration procedure was also used to evaluate the various inflow meters under the full range of flow rates. Both the pump stroke counters and pump speed counters were calibrated during the procedure. This resulted in a linear calibration curve based on the pump efficiency during the procedure. The calibration was not expected to remain accurate as the pump efficiency changed with drilling parameters such as temperature, pressure, mud properties, and seal wear. The performance of the Doppler ultrasonic flowmeter was also evaluated during the calibration procedure.

\section{Data Acquisition Strategy}

During data acquisition, the data were read and displayed once every second; however, data storage intervals were much longer. Initially, data were stored at five-minute intervals during normal operations and at one-minute intervals during periods of measured lost circulation or production. During the course of the field work, it was determined that a data storage interval of one minute would best capture transducer operation during all drilling conditions. Both instantaneous and average data were displayed on the screen and stored to disk. The average data were tied to data storage such that the averages were reset every time data storage occurred. Thus, data averages were a running average of all data collected since the last data storage.

Even during steady drilling operations, transducer signals in the field were not steady. A standard RC filter with a $22-\mu \mathrm{F}$ capacitor and a $100-$ to $200-\mathrm{k} \Omega$ variable resistor (resulting in a 2.2- to 4.4-second time constant) was installed on the rolling float meter to smooth out inherent unsteadiness. The signals from the magnetic flowmeters, acoustic level outflow meter, and paddlemeter were conditioned using a first-order digital filter formula with an equivalent time constant of approximately 27 seconds.

\section{FIELD TEST RESULTS}

\section{Elowmeter Calibration and Normal Drilling Conditions}

The two magnetic flowmeters measuring drilling fluid inflow were used as standards for evaluating the remaining transducers. The magnetic flowmeters have a rated accuracy of at least $1 \%$ of the total span, and their performance during the field test generally confirmed this. For approximately two days during the drilling operation, however, the magnetic flowmeters measured a flow rate consistently $0-5 \%$ lower than the other inflow and outflow meters in the system. During this time period, the magnetic flowmeters also read flow rates of up to 40 gpm $(2.5 \mathrm{~L} / \mathrm{s})$ when the pumps were shut off. Because the drilling crew was having problems with the mud cleaning system at that point, it was possible that fines were settling out in the magnetic flowmeter flow lines, thereby disturbing the magnetic fields and reducing the accuracy of the meters. When the mud cleaning system was repaired, the magnetic flowmeters again measured accurately. Since the magnetic flowmeters were by necessity installed in a horizontal line, they were susceptible to silting. Certainly it would have been preferable to install the meters in a vertical position; however, the flowmeters' pressure limitations required installation on the pump inlet line.

During normal drilling operations, the efficiency of the pumps (calculated by comparison with the magnetic flowmeter inflow measurements) varied by as much as $10 \%$, from $86 \%$ to $96 \%$. The efficiency was not a function of operating time, and varied by as much as $5 \%$ on any given day. In addition, factors such as the presence of air in the drilling mud reduced the pump efficiency to values as low as $65 \%$ for periods up to three hours.

The Doppler ultrasonic flowmeter calibration showed significant scatter and error in readings obtained throughout the flow rate range. The meter measured rates as much as $50 \mathrm{gpm}$ high at low flow rates, and $200 \mathrm{gpm}$ or $35 \%$ high at higher flow rates. The meter used in this study was designed with a sensitive pick-up for use with clean fluids, making it extremely susceptible to electrical noise and vibrations. As a drilling site is an extremely "noisy" environment, the Doppler meter never operated in a range in which it was not affected by electrical and vibrational noise.

Shown in Figure 5 are typical field calibration data obtained with the paddlemeter. At any given flow rate, the readings from the paddlemeter had significant scatter, sometimes as high as $35 \%$ of the average readings. Due to this scatter, there was significant overlap of voltage readings at various flow rates, making accurate calibration of the meter impossible. The paddlemeter, therefore, often produced flow rate errors of $\pm 15 \%$ of the actual flow rate, even when readings were averaged over periods of $1-5$ minutes.

The acoustic level meter's field calibration data resulted in a curve similar to that of the paddlemeter, however, during calibration, the meter readings had a scatter of approximately $4 \%$, resulting in a fairly accurate calibration curve. Calibration of the meters was generally done after an extended period of non-drilling operations, such as tripping, where wellbore circulation was less constant than during drilling. As a result, the temperature of the air in the retum flow line was significantly lower during calibration than during normal drilling operations. As drilling resumed, the temperature in the return flow line would increase, thereby increasing the acoustic velocity of the air inside the pipe. The increased velocity would cause the meter to sense a higher fluid level and, therefore, a high flow rate. Just after calibration the acoustic meter would provide accurate readings, but as drilling proceeded, the meter would begin to read as much as $8 \%$ high.

The field calibration data obtained with the rolling float meter also resulted in a third-order polynomial calibration curve. During calibration, the meter readings had a scatter less than $2 \%$ of the average readings, resulting in an excellent calibration. As predicted by laboratory testing, the transducer readings were unaffected by temperature or changes in mud properties during 
drilling. Typically, the meter read within an apparent accuracy of $\pm 2 \%$ and was often as accurate as $\pm 0.5 \%$. There were often periods when the rolling float meter reading would match the magnetic flowmeter reading within $\pm 5 \mathrm{gpm}( \pm 0.3 \mathrm{~L} / \mathrm{s})$ out of a total flow rate of approximately $900 \mathrm{gpm}$.

Problems with the prototype flowmeter were encountered and corrected during the field test. When the return mud temperature reached approximately $145^{\circ} \mathrm{F}\left(63^{\circ} \mathrm{C}\right)$, the sidewalls of the polyethylene float softened sufficiently to warp and become disengaged from the hubs and bearings. This problem was corrected by filling the hollow float with polyurethane foam to provide structural rigidity at higher temperatures. One of the float's bearings also experienced periodic sticking toward the end of the test period, causing erroneous readings. Since the problem lasted for only brief periods of time, it was not deemed serious enough in the short remaining test time to warrant repair.

A comparison of typical performance of the three outflow meters is provided in Figure 6. Shown here are the magnetic flowmeter inflow rates for a typical day, along with outflow rates as measured by the acoustic level meter, paddlemeter, and rolling float meter. The drilling report for that day indicates a stable pit level, so no measurable fluid loss or gain was detected. The rolling float meter measured outflow within $-1 \%$ to $+2 \%$ of the magnetic flowmeter inflow rate. The acoustic meter read consistently $2 \%$ to $8 \%$ high, while the paddlemeter read consistently $2 \%$ to $9 \%$ low. Although the rolling float meter experienced some problems due to its developmental status, once those problems were resolved, it proved to be the most accurate of the three outflow meters tested.

\section{Detection of Abnormal Hydraulic Conditions}

The opportunity to test the outflow meters under abnormal hydraulic conditions such as lost circulation and wellbore fluid production presented itself when both these conditions occurred in the same wellbore within a few days of each other. The drilling report for August 30, 1991, notes a pit loss of $200 \mathrm{bbl}$ of drilling fluid. The measured magnetic flowmeter inflow rates are shown plotted with the rolling float meter, acoustic meter, and paddlemeter, respectively, in Figures 7-9. Both the rolling float meter and the acoustic level flowmeter (Figures 7 and 8) measured a drop in flow rate relative to the magnetic flowmeter inflow readings. According to these meters, the loss began at approximately 6:30 pm on August 30 and ended just after 4:00 am on August 31, after the addition of lost circulation material (LCM) to the drilling mud. Loss rates up to $56 \mathrm{gpm}$, or $6 \%$ of the inflow, were detected. The drilling crew noted a drop in pit level at a drilling depth of $6140 \mathrm{ft}$. This was approximately 9:00 pm, $2 \frac{1}{2}$ hours after the outflow meters first detected a loss. The paddlemeter (Figure 9) measured a lower flow rate than the magnetic flowmeter throughout the entire time period. The actual loss and subsequent recovery of circulation was not detected by the paddlemeter.

The abnormally high rolling float measurement (Figure 7) between 4:00 am and 6:00 am on August 31 was due to a bearing sticking on the float. If the float is not free to spin, it rides higher in the water resulting in a higher flow rate reading.

Wellbore fluid production during drilling was detected on September 6 and 7, when the mud logger's pit level report indicates an increase of $200 \mathrm{bbl}$. Again, the measured magnetic flowmeter inflow rates are shown plotted with the rolling float meter, acoustic meter, and paddlemeter, respectively, in Figures 10-12. Measurements from the rolling float meter (Figure 10) indicated about 5-6\% greater outflow than inflow starting at approximately $2: 00 \mathrm{pm}$ and ending near midnight on September 6. Since the acoustic level meter (Figure 11) read as much as $7 \%$ high throughout the day, the wellbore production of fluid was not detected with this meter. The same is true for the paddlemeter (Figure 12), which read approximately 5-7\% low during the entire time period.

\section{DISCUSSION AND CONCLUSIONS}

Based on the experience of the field test described above, it would appear that the magnetic flowmeter is nearly ideal for measuring drilling fluid inflow rates of water based drilling mud. The relatively high cost of magnetic flowmeters, however, may make them impractical for routine use. For instance, the 10-inch magnetic flowmeters used in this field test cost $\$ 8700$ each. In addition, the magnetic flowmeters are limited to use only with water-based drilling mud.

On the basis of ease of installation, minimum interference, and applicability to all drill rigs, the Doppler ultrasonic flowmeter would be the best option for inflow rate measurement. These meters are non-invasive and theoretically are not affected by fluid properties; however, we were unable to obtain accurate measurements with this flowmeter. This agrees with our experience at other field sites. Although we have obtained accurate readings with this type flowmeter at times, we have not found it reliable enough to use by itself in the rig environment.

Although the stroke counter and rotary speed transducer are both reliable in measuring the pump speed, only an accurate knowledge of pump efficiency allows the pump speed to be accurately converted to flow rate. Because pump efficiency cannot be determined without some independent means for measuring the flow rate, and because of the effects of fluid properties and pump speed, pressure, and seal wear on pump efficiency, it is difficult to obtain highly accurate flow rate measurements with these meters. Since most significant changes in pump efficiency occur relatively slowly, however, these meters can be used together with an accurate outflow transducer and frequent calibration procedure to detect rapid changes in delta flow. Mud pump speed transducers, therefore, remain the most practical flowmeters to use for inflow measurements on the rig.

The pump rotary speed transducers used in this field test were found to be preferable to the conventional pump stroke counters. The rotary transducers provide a pulse output with a frequency 287 times the pump stroke frequency. Consequently, the response of the rotary transducers to changes in pump speed is much faster than that of the pump stroke counters. Although not all pumps can be easily fitted with rotary transducers, we recommend their use whenever possible.

Of the three outflow meters tested, the rolling float meter was by far the most accurate. This meter was found to measure the outflow rate within an apparent accuracy of at least $2 \%$, and often within $1 / 2 \%$. It was found capable of detecting very small gains and losses in drilling fluid relative to inflow rates. Some reliability problems were encountered with this meter, but those were due primarily to its developmental status and were temporarily solved in the field. Final solutions to these problems are discussed below.

The acoustic level meter was found to be a fairly reliable meter for outflow measurements, detecting some, but not all, the fluid gains and losses detected by the rolling float. In order to attain the accuracy provided by the rolling float, however, it would be necessary to correct the acoustic level meter readings for the effects of air temperature. In fact, at least one service company currently uses an acoustic level meter in this manner, taking multiple temperature measurements in the air space between the fluid surface and the acoustic transducer and using the data to correct the transducer readings $[1,2]$. Our field test demonstrates that if the acoustic data are not corrected, accuracies better than $2-8 \%$ are not likely, particularly with hot wells. It is therefore necessary to monitor and analyze several channels of data in order to properly utilize the acoustic level meter.

Although extremely reliable, the paddlemeter evaluated in this field test did not demonstrate sufficient accuracy to be used for delta flow measurement. Oscillations of the paddle due to transient surface waves in the return flow line caused scatter in 
the paddlemeter signal that did not permit accurate calibration. Measurement accuracy was rarely better than $5 \%$, and often ranged from 10 to $15 \%$. The meter did not detect any of the fluid gains or losses detected with the other outflow meters. Although the paddlemeter provides a highly reliable qualitative measure of flow rate (i.e., high-flow, low-flow, or no-flow), it was not found to have the sensitivity needed to determine quantitative levels accurately.

Because of the outstanding accuracy demonstrated by the rolling float meter and the simplicity of its design and operation, this flowmeter has undergone further development since the field test. By eliminating the rotary sensor inside the float, the use of a solid polyurethane float became possible. A silicone rubber cast of the original float used in the field test was made and subsequently used to cast the float's replica out of two-part, 6$\mathrm{lb} / \mathrm{ft}^{3}(0.1 \mathrm{gm} / \mathrm{cc})$ polyurethane foam. The float will undergo extensive $\mathrm{lab}$ testing and further development. Although it is to early to predict the ultimate suitability of the foam float for routine field use, it is certain that a suitable low-cost wheel can be replicated in some manner for this purpose. Once this development is complete, the rolling float meter will be further tested in the field.

\section{ACKNOWLEDGMENTS}

This work was sponsored by the U. S. Department of Energy, Geothermal Technologies Division, at Sandia National Laboratories under Contract DE-AC04-76DP00789. The assistance of John Finger and Ron Jacobson during field testing is gratefully acknowledged.

\section{REFERENCES}

1. Orban, J.J., Zanker, K.J., and Orban: A.E., "New Flowmeters for Kick and Loss Detection During Drilling," SPE 16665, Presented at the 62nd Annual Technical Conference and Exhibition of the Society of Petroleum Engineers, Dallas, TX, September, 1987.

2. Orban, J.J., and Zanker, K.J.: "Accurate Flow-Out Measurements for Kick Detection, Actual Response to Controlled Gas Influxes," IADC/SPE 17229, Presented at the IADC/SPE Drilling Conference, Dallas, TX, FebruaryMarch, 1988.

3. Speers, J.M., and Gehrig, G.F.: "Delta Flow: An Accurate, Reliable System for Detecting Kicks and Loss of Circulation During Drilling," SPE/IADC 13496, Presented at the SPE/AADC Drilling Conference, New Orleans, LA, March, 1985.

4. Maus, L.D., Peters, B.A., and Meador, D.J.: "Sensitive Delta-Flow Method Detects Kicks or Lost Returns," Oil and Gas Journal, August 20, 1979, pp. 125-132.

5. Bode, D.J., Noffke, R.B., and Nickens, H.V.: "WellControl Methods and Practices in Small Diameter Wellbores," Journal of Petroleum Technology (November 1991), pp. 1380-1386.

6. P.L. Moore: Drilling Practices Manual, Penn Well Books, Tulsa, OK, 1974.

7. Loeppke, G.E., Schafer, D.M., Glowka, D.A., Scott, D.D., Wright, E.K., and Wernig, M.D.: "Development and Evaluation of a Meter for Measuring Return Line Fluid Flow Rate During Drilling," Sandia National Labs Report, SAND 91-2607, January 1992. 


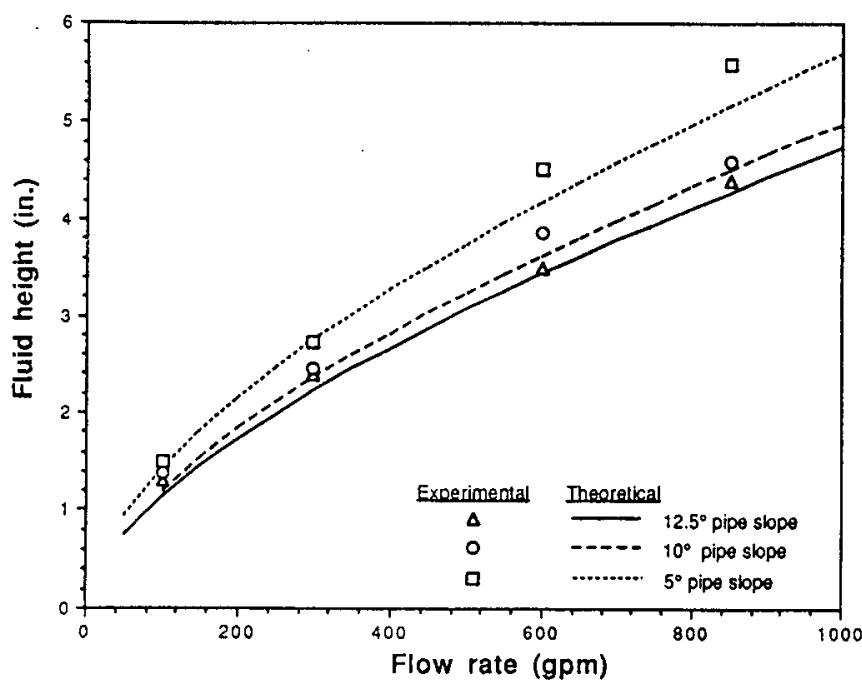

Figure 1. Theoretical and experimental fluid height in a smooth, 9.5 in. diameter, inclined pipe at a location 3 feet from the fluid entrance [after Ref. 7].

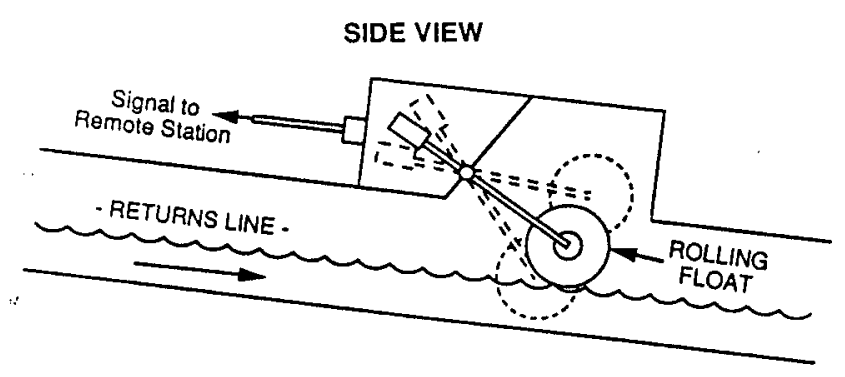

END VIEW

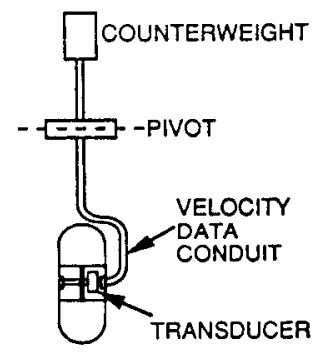

Figure 2 - Schematic of the prototype rolling float meter.

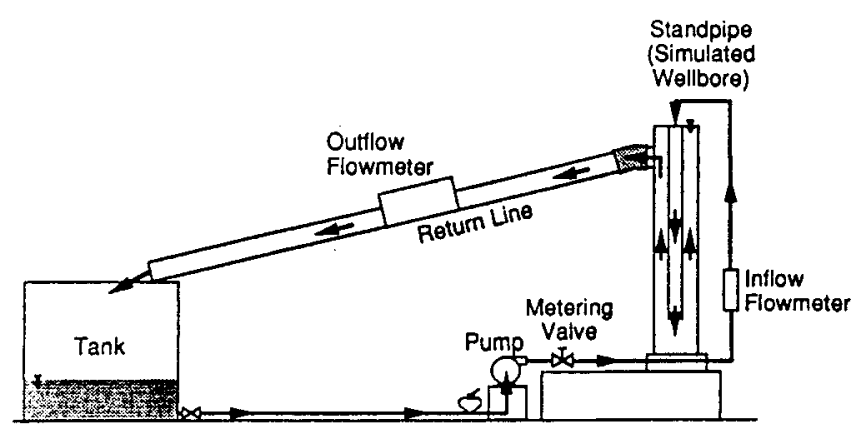

Figure 3- Schematic of the Welibore Hydraulics Flow Facility.

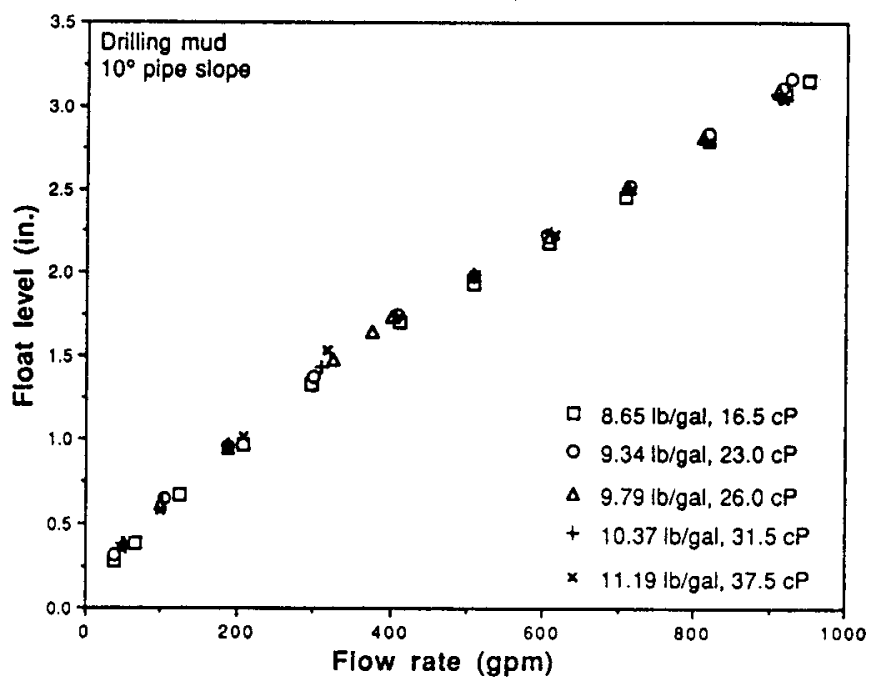

Figure 4 - Effects of fluid properties on the rolling float meter height measurement.

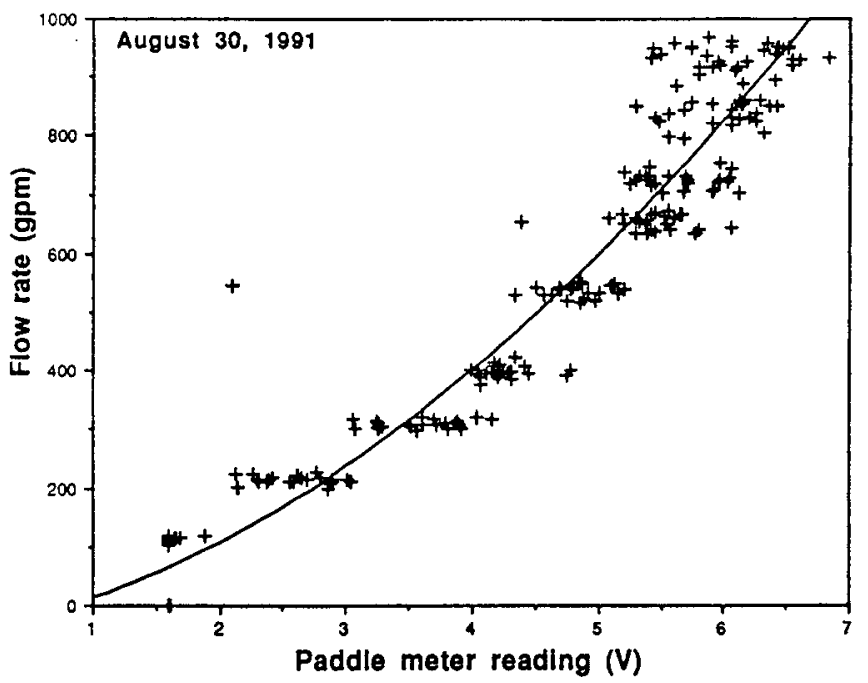

Figure 5 - Flow rate calibration of the paddlemeter at the Long Valley Exploratory Well.

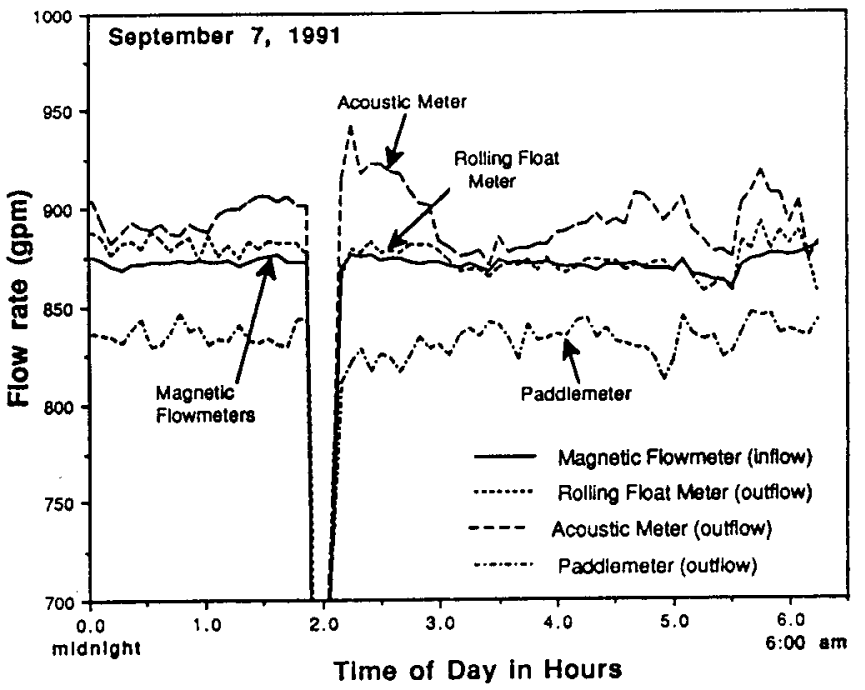

Figure 6 - Comparison of drilling fluid inflow and outflow rates during nomal drilling at the Long Valley Exploratory Well. 


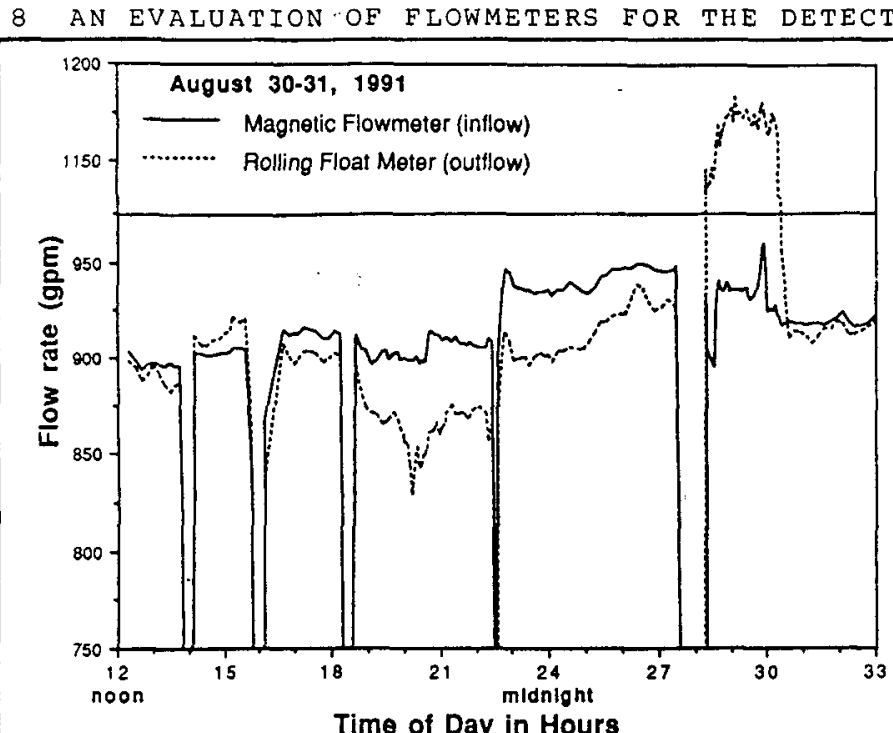

Figure 7 . Comparison of magnetic flowmeter inflow and rolling float meter outflow rates during lost circulation at the Long Valley Exploratory Well.

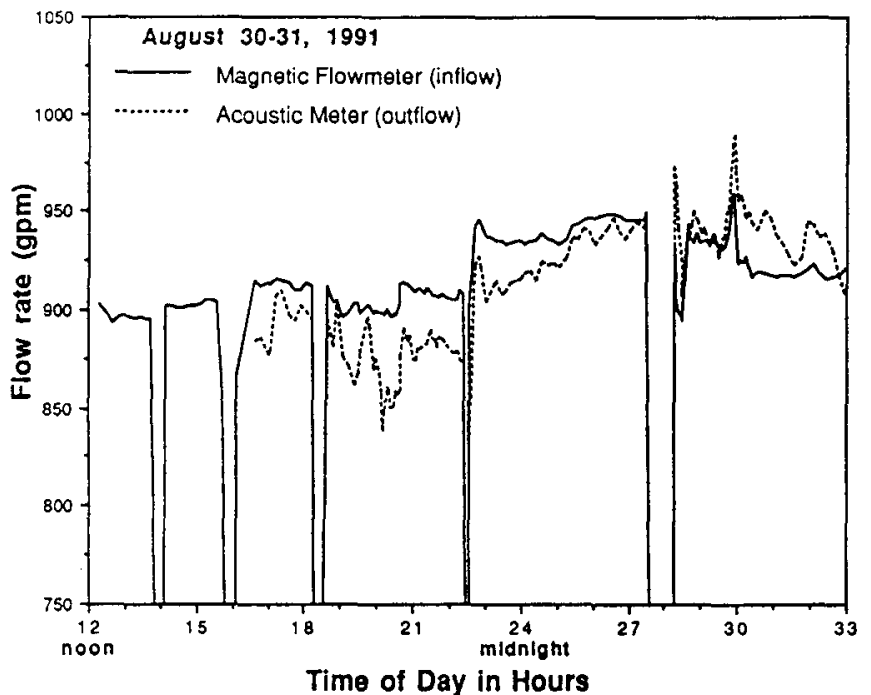

Figure 8 - Comparison of magnetic flowmeter inflow and acoustic meter ourflow rates during lost circulation at the Long Valley Exploratory Well.

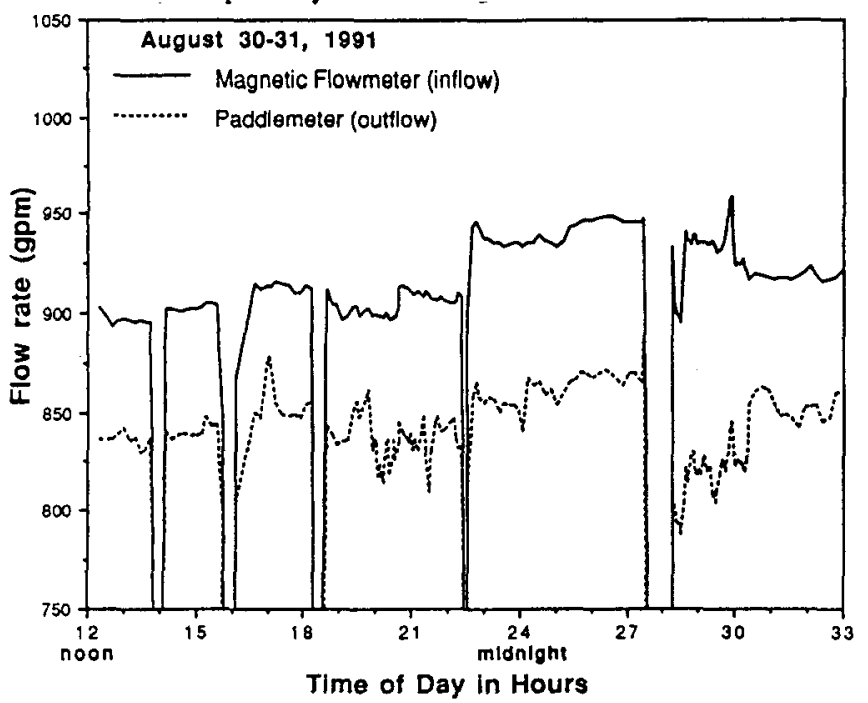

Figure 9. Comparison of magnetic flowmeter inflow and paddlemeter outflow rates during lost circulation at the Long Valley Exploratory Well.

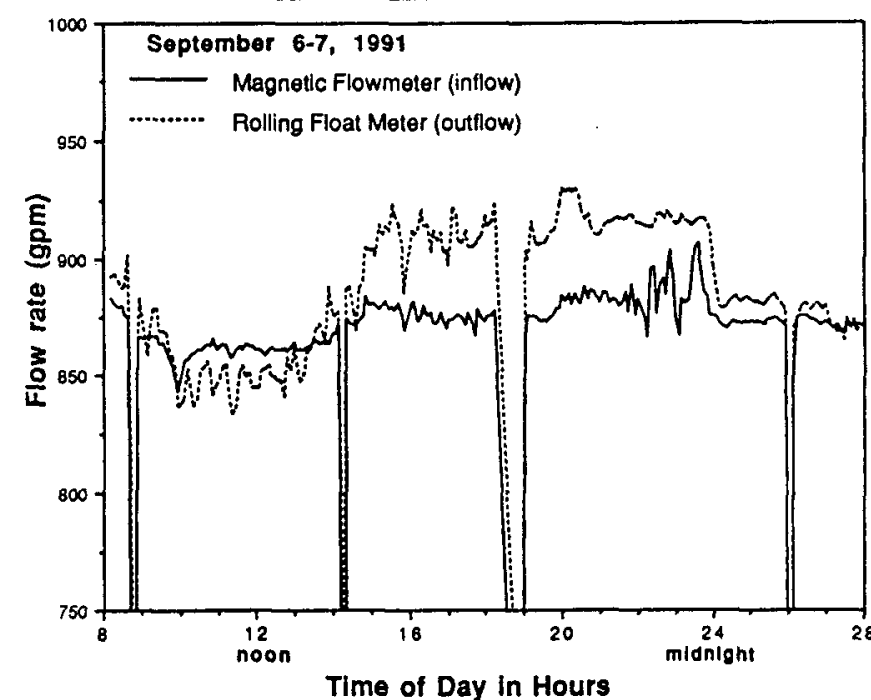

Figure 10 - Comparison of magnetic flowmeter inflow and rolling float meter outflow rates during wellbore fluid production at the Long Valley Exploratory Well.

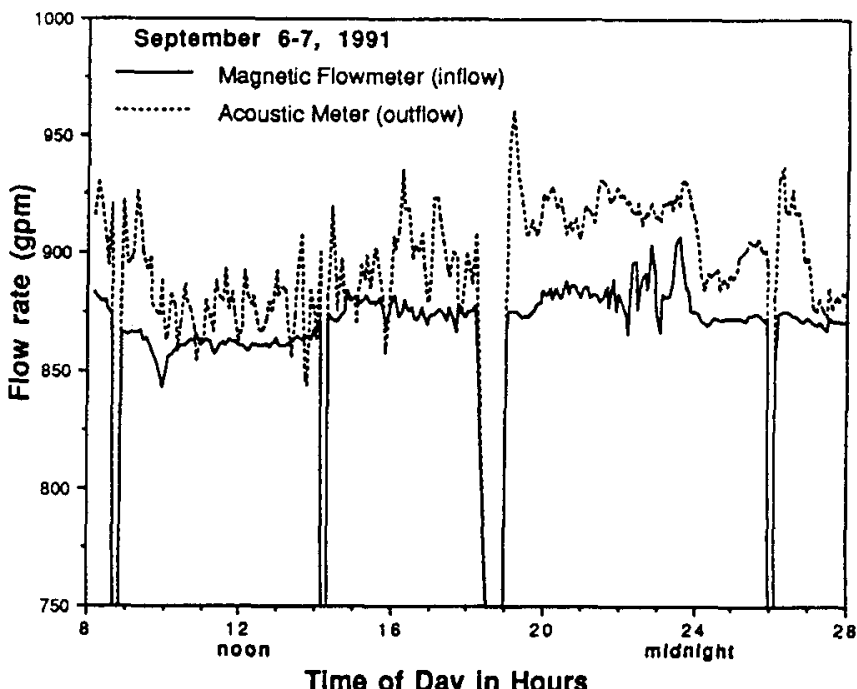

Figure 11 - Comparison of magnetic flowmeter inflow and acoustic meter outflow rates during wellbore fluid production at the long Valley Exploratory Well.

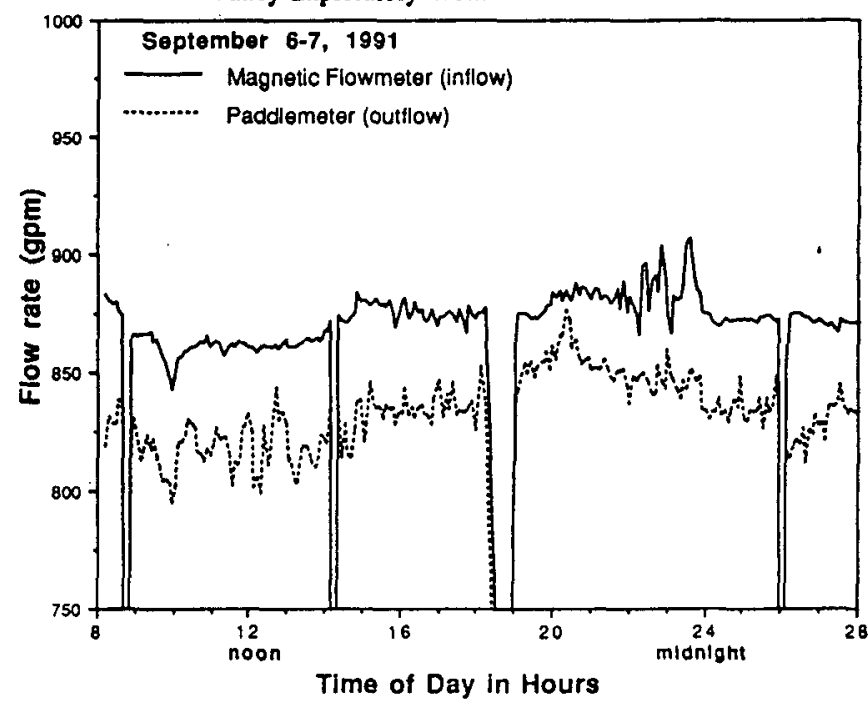

Figure 12 - Comparison of magnetic flowmeter inflow and paddlemeter outflow rates during welibore fluid production at the Long Valley Exploratory Well. 